\title{
The bird's-eye perspective: how do district health managers experience the impact of family physicians within the South African district health system? A qualitative study
}

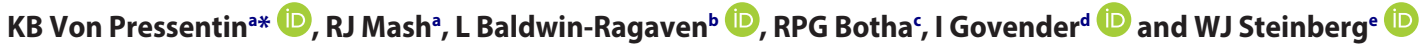 \\ ${ }^{a}$ Division of Family Medicine and Primary Care, Stellenbosch University, Cape Town, South Africa \\ ${ }^{b}$ Department of Family Medicine, School of Clinical Medicine, University of the Witwatersrand, Johannesburg, South Africa \\ 'Department of Family Medicine, University of Pretoria, Pretoria, South Africa \\ ${ }^{d}$ Department of Family Medicine, Sefako Makgatho Health Sciences University, Pretoria, South Africa \\ e Department of Family Medicine, University of the Free State, Bloemfontein, South Africa \\ *Corresponding author, email: kvonpressentin@sun.ac.za
}

Background: Health policy-makers in Africa are looking for local solutions to strengthen primary care teams. A South African national position paper (2015) described six aspirational roles of family physicians (FPs) working within the district health system. However, the actual contributions of FPs are unclear at present, and evidence is required as to how this cadre may be able to strengthen health systems.

Methods: Using semi-structured interviews, this study sought to obtain the views of South African district health managers regarding the impact made by FPs within their districts on health system performance, clinical processes and health outcomes. Results: A number of benefits of FPs to the health system in South Africa were confirmed, including: their ability to enhance the functionality of the local health system by increasing access to a more comprehensive and coordinated health service, and by improving clinical services delivered through clinical care, capacitating the local health team and facilitating clinical governance activities.

Conclusions: District managers confirmed the importance of all six roles of the FP and expressed both direct and indirect ways in which FPs contribute to strengthening health systems' performance and clinical outcomes. FPs were seen as important clinical leaders within the district healthcare team. Managers recognised the need to support newly appointed FPs to clarify their roles within the healthcare team and to mature across all their roles. This study supports the employment of FPs at scale within the South African district health system according to the national position paper on family medicine.

Keywords: family physicians, healthcare system, primary health care, healthcare team, leadership

\section{Background}

The 1978 Alma-Ata declaration represented a global commitment to primary health care (PHC). ${ }^{1}$ Dr Margaret Chan, in her introduction to the 2008 World Health Report: 'Primary Health Care-Now more than Ever', stated, in reference to Alma-Ata, that,'despite enormous progress in health globally, our collective failures to deliver in line with these values are painfully obvious and deserve our greatest attention.2 Since then, there have been renewed global efforts towards more integrated people-centred PHC, and attaining the Sustainable Development Goals, including universal health coverage. ${ }^{3,4}$

One of the strategies to strengthen PHC is to review the composition and deployment of the primary care workforce. ${ }^{5}$ Health policy-makers in South Africa are faced with a quadruple burden of disease: HIV/AIDS and tuberculosis; maternal and child health; injuries and violence; and non-communicable chronic diseases. ${ }^{6}$ Internationally, there is increasing support for PHC services that are provided by multidisciplinary teams led by doctors with postgraduate training in family medicine. ${ }^{2,7-11}$ Paradoxically (and in line with the inverse care law), PHC teams on the African continent lack this cadre of specialist-trained family physicians (FPs).,12 The majority of primary care doctors working in both private and public sectors do not have a postgraduate qualification in family medicine. ${ }^{7,8,13,14}$
The academic discourse around the roles and potential contribution of African family physicians is ongoing. Historically, the training and employment of FPs in African health systems has occurred asynchronously, with consensus on academic training outcomes preceding the official deployment policies..$^{15-17}$ The African continent's academic leadership have engaged with a number of processes to obtain consensus on the roles and contributions of FPs, and advocate for their training and deployment within the evolving healthcare landscape. ${ }^{17,18}$ In South Africa, the specialty was officially recognised by the Health Professions Council in 2007.,19 This event enabled the development of accredited postgraduate training according to a set of nationally agreed unit standards and learning outcomes. ${ }^{8,19-21}$ Graduates are expected to fulfil six key roles (see Figure 1): care provider, consultant, capacity builder, clinical trainer, clinical governance leader and champion of community-oriented primary care (COPC). ${ }^{8,21}$ In 2015, a national position paper made recommendations to the South African National Department of Health (NDOH) on how best to deploy FPs as expert generalists within the District Health System (DHS). ${ }^{8}$ The South African academic family medicine departments are also playing a strong leadership role in supporting the establishment of family medicine training programmes elsewhere in Africa. ${ }^{22,23}$ 
Care provider: Competent in being able to work throughout the district.

Consultant: Acts as a consultant to the primary care and district hospital services.

Capacity builder: Teaches, mentors, supports and develops other practitioners.

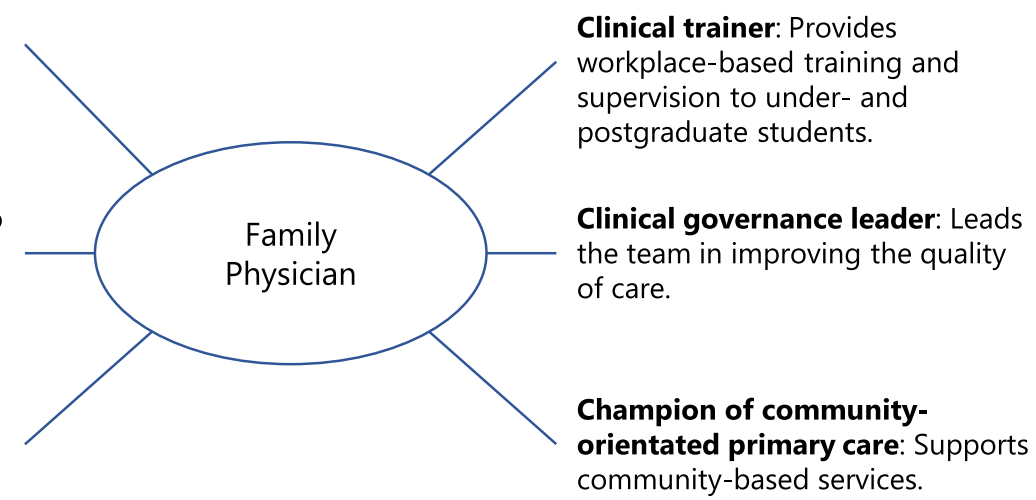

Clinical trainer: Provides

workplace-based training and supervision to under- and postgraduate students.

Clinical governance leader: Leads the team in improving the quality of care.

community-based services.

Figure 1: Six roles of the South African family physician. ${ }^{8}$

The opinions of African healthcare leaders on the role of FPs in their health systems were published previously. ${ }^{13,24}$ The literature on this topic described different levels of support coupled with uncertainty and even apprehension regarding the contribution of this discipline. ${ }^{8}$ The official policy direction is often not aligned with these opinions or the aforementioned position statements by the academic leadership. ${ }^{8,25}$ In South Africa, policy documents acknowledge the role of FPs in terms of clinical governance and leadership within the DHS. ${ }^{26,27}$ Their role within district hospitals and at district level as members of the district clinical specialist teams (DCST) is clearer than their contributions to primary care and community-based services, which remains less well defined. ${ }^{8,28,29}$ During interviews held in 2012 and 2013 in the Western Cape Province of South Africa, district health managers agreed on the positive impact of FPs on the quality of clinical processes, specifically in relation to HIV/AIDS, tuberculosis, maternal and child health, non-communicable diseases and mental health. ${ }^{30,31}$ In addition, FPs appear to have some impact on health system performance in terms of improved access to care, better coordination and the provision of a more comprehensive and efficient service. ${ }^{30,31}$

A national research project has attempted to provide evidence from the South African context on the early impact of FPs within the DHS. ${ }^{32}$ The authors conducted four different studies, including: a cross-sectional observational study comparing DHS facilities exposed to FPs to matched controls; a survey of FPs using a validated 360-degree impact assessment tool; correlation of FP supply with routine district health indicators; and interviews with district health managers. This article presents the findings from district manager interviews, while the results from the other studies are reported elsewhere. ${ }^{33-35}$ This study aimed to evaluate the impact of FPs within the DHS of South Africa from the perspective of the district managers in the following three domains: health system performance, clinical processes and health outcomes.

\section{Methods}

\section{Study design}

This was a phenomenological qualitative study using semistructured interviews with district managers. The consolidated criteria for reporting qualitative research (COREQ) checklist was used to guide this report. ${ }^{36}$

\section{Setting}

This study was conducted in the DHS of the South African public health sector in seven of the country's nine provinces according to the provincial footprint of the universities collaborating in the study. Each province consists of a number of districts defined geographically by the South African Constitution. ${ }^{37,38}$ Each health district is sub-divided into defined sub-districts, each of which usually has a district hospital (DH) or community health centre (CHC) that serves several fixed or mobile smaller PHC clinics. DHs typically have inpatient services with male, female, child and maternity wards, as well as operating theatres, and outpatient and emergency departments. CHCs are usually larger primary care facilities with a multidisciplinary team, often including a FP and can also include dedicated 24-h emergency centres and/or midwife obstetric units (MOUs). PHC clinics are smaller facilities generally run by nurses with occasional outreach support from doctors, typically primary care doctors or medical officers (MOs) with no postgraduate training. Most primary care consultations in the public health sector (more than $80 \%$ ) are with nurses who thus become the first point of contact for patients in the public health system. ${ }^{39}$ Community-oriented primary care (COPC) services are also emerging with community health workers and nurses as team leaders taking responsibility for a certain number of households within a defined municipal ward. ${ }^{40}$ These wardbased outreach teams (WBOTs) are linked to local $\mathrm{CHCs}$ and primary care clinics. ${ }^{14,38}$

In terms of reflexivity, the research team consisted of FPs engaged with the training of FPs for the DHS. Two of the authors, KvP and WJS, helped conduct the interviews. All interviewees were encouraged to voice honest views. KvP conducted the qualitative data analysis under the supervision of RM. KvP is an $\mathrm{FP}$ and $\mathrm{PhD}$ student, has experience and training in qualitative research methods, and took care to conduct the analysis in a rigorous manner.

\section{Characteristics and selection of participants}

District managers (at director or chief director level) for all FPcontaining districts in each of the seven provinces were invited to participate in the study. District managers (DMs) are the highest ranking members of the district management team and are responsible for implementing policy decisions and determining expenditure priorities for the district. Chief directors (CDs) are higher-ranking DMs who oversee a cluster of health districts and/or substructures within a defined geographical area. DMs and CDs therefore have a bird's-eye view of the performance of their district as a whole. This vantage point allows them to reflect on how FPs and other interventions impact on the performance of their districts. All eligible DMs were approached via the collaborating academic family medicine departments. Informed consent was obtained from all DMs who participated. 
Table 1: Interview guide

1. What has been your experience of family physicians in your district so far?

2. What impact, if any, do you think your family physicians have had on the quality of clinical care (HIV/AIDS, TB, STIs, NCDs, maternal, child, injury, trauma and mental health)?

3. What impact, if any, do you think your family physicians have had on the performance of the district health system or facilities (access, continuity, coordination, comprehensiveness, other)?

4. Do you think that your family physicians are having any impact on health outcomes in your district (mortality)?

5. To what extent have the predicted roles of the family physician been seen in practice (care provider, consultant, capacity builder, clinical trainer, clinical governance leader and champion of community-oriented care)?

6. Have there been any unanticipated impacts or roles?

Abbreviations: AIDS: acquired immune deficiency syndrome; HIV: human immunodeficiency virus; NCDs: non-communicable diseases; STIs: sexually transmitted illnesses.

\section{Data collection}

Semi-structured face-to-face interviews were held between September 2014 and March 2016 depending on the readiness of each province and local Health Research Ethics Committee approval to conduct the research. The interview started with an open question, which explored the interviewee's experience of the FPs working in his/her district. Further potential questions focused on aspects of health system performance, clinical processes and health outcomes, as well as the six roles of the FP, and were contained in an interview guide (Table 1). Interviews were conducted by two co-authors, as well as five research assistants who were trained in qualitative interviewing. Interviews were held at a location convenient to the interviewee, in the language preferred by the interviewee (either English or Afrikaans) and were audiotaped.

\section{Data analysis}

All the interviews were transcribed verbatim in the original language of the interview. All the transcripts were checked against the original recording by the researcher. Qualitative data analysis used the framework method (familiarisation, develop a thematic index, coding source documents, charting, interpretation) and was assisted by ATLAS.ti ${ }^{\circledast}$ software (version 7.5.17) (http://www.atlasti.com/).41,42 Direct quotations from the interviews were identified to illustrate key points.

\section{Ethical considerations}

This study was approved by the Human Research Ethics Committee (Medical), Stellenbosch University (reference $\mathrm{S} 15 / 01 / 003)$, as well as by each partner institution. The seven provincial health authorities and research committees also gave permission to access the study setting (the full list is available as a supplementary file).

\section{Results}

Twenty-one district managers out of 36 eligible districts agreed to participate in this study (see Table 2). All seven provinces were represented.

\section{Health system performance}

Most DMs felt that FPs enabled better access to a comprehensive package of care at the appropriate level. This was achieved both directly, by providing care requiring a more advanced skills set closer to the community, and indirectly, by ensuring that
Table 2: Enrolment of district managers by province

\begin{tabular}{lcc}
\hline Province & $\begin{array}{c}\text { Number of eligible } \\
\text { districts }\end{array}$ & $\begin{array}{c}\text { Number of district } \\
\text { managers enrolled }\end{array}$ \\
\hline Free State & 5 & 2 \\
\hline Gauteng & 5 & 4 \\
\hline KwaZulu-Natal & 10 & 4 \\
\hline Mpumalanga & 3 & 3 \\
\hline Northern Cape & 4 & 1 \\
\hline North West & 4 & 2 \\
\hline Western Cape & 5 & 5 \\
\hline Total & 36 & 21 \\
\hline
\end{tabular}

appropriately capacitated healthcare workers were available at the primary care coalface. They thought that FPs ensured more appropriate referrals to specialist care and therefore improved the coordination of care between different levels of the health system. FPs also improved the flow of patients through the emergency centre of the district hospital to either the inpatient wards or the primary care platform:

The impact of family medicine on the performance of health services and health facilities has been very great in my view. We very rarely had specialists at primary health care level and the coming in of family medicine makes it very easy, because we are bringing somebody who would know what will happen in the next second, third and fourth stage in case we have got to refer the patient. So you are, you are actually increasing access of services, you're bringing a very comprehensive person who would understand what is needed for this patient. (DM, North West Province)

\section{Clinical processes}

The majority of DMs reported specific examples of how FPs contributed to the enhancement of clinical service delivery, specifically in the areas of chronic disease management (HIV/ AIDS, tuberculosis, mental health and non-communicable diseases), maternal and child health, and emergency care. FPs engaged with these clinical processes by creating competent multidisciplinary teams, performing applied research and audits, and developing locally relevant clinical governance activities:

... I'd like to zoom in to non-communicable diseases. They've really assisted us in terms of clinical upscaling of our staff. When they visit our facilities, they're not only seeing patients but they also make sure that when they pick up challenges around management of, of clients, we can say diabetic clients, or hypertensive clients, they do on-the-job training. And they also assist in terms of arranging formal in-service trainings, where they touch on topics relating to conditions that [are] of serious concern within our district. (DM, Mpumalanga Province)

\section{Family physician roles}

In general, the DMs were satisfied that the FPs were having direct patient contact, especially by seeing referred patients presenting more complicated or difficult cases. The DMs also appreciated the supporting role of FPs as consultants, supervisors and mentors to other members of the PHC team (nurses, doctors, GPs and foreign qualified doctors). However, one DM stressed that the FP should be more hands-on with clinical work as'you cannot sit and call yourselves consultants and you do not do work'. Some 
DMs also mentioned the value of FPs conducting consultant ward rounds in the district hospitals:

$$
\begin{aligned}
& \text {... their role particularly, we see it as more consultancy and } \\
& \text { mentoring. They also, I can also say they are a care provider } \\
& \text { as well because they also see patients. But for us the } \\
& \text { consultancy role and mentoring role that they play has } \\
& \text { actually assisted us in terms of the standard of care that } \\
& \text { we're providing to our patients. (DM, Mpumalanga Province) }
\end{aligned}
$$

DMs mentioned various healthcare worker categories that benefited from the in-service training and capacity-building efforts of the FPs, including nurses, doctors, nursing and medical students, family medicine registrars and community health workers.

... we've got ... primary health care students in our facility; so they conduct in-service trainings as well and they actually help them out to, to do other practicals with students. (DM, Gauteng Province)

The clinical governance role featured strongly in the interviews, with numerous examples cited of how FPs assist the management structures with audits, operational research, interpretation of routinely collected data, investigation of adverse events, and 'harmonising'the services within the sub-districts by implementing protocols and standard operating procedures (SOPs):

She does audits which were not done in the past.... She does clinical governance by reviewing the adherence to protocols around chronic care, tuberculosis, etc. And she addresses the gaps identified. And she also looks at the quality of referrals made by the doctors. (DM, Western Cape Province)

The contribution of FPs to developing COPC and supporting WBOTs featured less strongly. DMs mentioned some examples of FPs who were engaging with this role, specifically in the Gauteng, Mpumalanga and KwaZulu-Natal provinces. These activities could be in conjunction with university, governmental or nongovernmental organisations:

In terms of continuity of care, family physicians, they also go into the ward, into the houses, because Doctor [Surname] is the one who is going to, when these community health workers and the team leaders refer their patients, and then they have got a difficult patient at home, Doctor [Surname] literally goes into the family to go and see the, the patient and as he refers the patient to the hospital, he is able also to follow the patient into the hospital to see what is happening and also back referral into, into the district or into primary health care. (DM, Gauteng Province)

\section{Clarifying roles and expectations}

DMs spoke about the range of employment options available to FPs both within and outside the DHS. FPs might be employed at the level of the district, either as a member of the DCST or at the district office, at the sub-district level, within the primary care facilities or district hospital. Some FPs were working outside the DHS at the referral hospital, where they worked in the outpatient department. Some FPs were employed in clinical manager positions and not as FPs. Each employment option came with different perceptions on what roles the FP should fulfil.

Dual or joint appointments with the university raised the additional concern that some FPs spent more of their energies on teaching activities and that the district clinical services were not 'getting the time out of them'. Other DMs reported on how a formal communication structure between DMs and academic family medicine departments enabled ongoing conversations around balancing the tensions of adequate student supervision and service delivery demands. Some DMs mentioned examples of how the presence of students benefited the DHS, such as student-supported clinical services, university-built infrastructure and postgraduate operational research:

So I think the university also has a better understanding now that we need to prioritise service delivery. But you need to have a well-balanced approach here. And not to harm the student in the process in terms of curriculum requirements. So yes, we are learning all the way in the rural areas. You know how to best manage students on the platform.... I really don't think we can afford in rural areas to be having the luxury of family physicians operating as academic consultants you know. (DM, Western Cape Province)

At the level of the district, a greater focus on clinical governance and coordination was expected. Some DMs reported on the uncertainty among existing doctors in the DHS on how the FPs will be able to complement the existing service. A North West DM also reported on the interplay between FPs and the GPs contracted as part of the National Health Insurance (NHI) piloting process, where the NHI GPs were perceived to be more engaged with the primary care facilities' clinical governance activities. Three of the Western Cape DMs also reflected on how FPs and clinical managers complemented each other in the larger subdistrict service platforms.

FPs often have to take the lead in helping their colleagues and managers understand 'how broad their role is'. A KwaZulu-Natal DM reflected on how it may not be 'a nice position to be in ... having them like they're fighting for their position'. A Gauteng DM was wondering whether 'I'm expecting too much from them', by hoping that FPs will be functioning at the forefront in the community and not in the health facility. A Western Cape DM highlighted the role of the DM in helping the DHS team to 'focus on the roles and responsibilities from the start'. Another Western Cape DM was concerned that FPs would be associated only with a narrow clinical focus of chronic disease management. This was echoed by a Gauteng DM in the quote below, which emphasises the difference in roles of FPs and MOs:

But however for me I think they are not doing what is expected of them. Because they work as if they're normal, they don't do anything you know more than an ordinary MO. I used to challenge them to say that you need to be, you need to transcend, you don't have to be like an ordinary $\mathrm{MO}$, because medical officers you know that their work is just to look at, you know push the queue and look at the patients and whatever. (DM, Gauteng Province)

\section{Unanticipated roles}

Many of the DMs were able to highlight examples where FPs took on additional duties. Some DCST FPs fulfilled the role of other members of the DCST such as the obstetrician, particularly where such positions were vacant. Other FPs acted as consultants for other disciplines, such as internal medicine, where such specialties were not accessible to the clinical team. Other unanticipated roles included the FP's value in addressing human resources and other managerial tasks, including the line management of clinical staff. Some FPs impressed their DMs with 
their levels of engagement with research activities, especially where the research focused on operational issues.

\section{Perceived impact of family physicians on health outcomes}

Some of the DMs were able to indicate specific areas where FPs were making a perceived impact, specifically in maternal health (reduction in Caesarean rate) and primary health care (better access to a more comprehensive service). The DMs acknowledged that the health outcomes of the community will be'a much more long term thing', as 'there are just not enough' FPs. Their ability to influence the team and ensure a well-organised service were cited as examples of them making a 'huge difference as part of a complex system'. Some DMs mentioned potential indicators that may help to gauge the impact of the FPs, such as: maternal mortality/morbidity, infant mortality rate, TB cure rate and chronic disease management outcomes. One Western Cape DM stressed that the FP's qualities which she/he 'brings to the table ... [are] not measurable in terms of statistics of [number of] patients seen', requiring a more nuanced or sophisticated analysis of what is going on.

\section{Interplay between context and family physicians}

A recurring theme was the issue of the FP's ability to influence his/her context. An expectation of FPs in the DHS is that they will help the healthcare system to improve, expand and develop. FPs who were seen to be 'at the mercy of the system' were those lacking leadership skills and not able to integrate themselves into the clinical team. Additional constraints on the FP's ability to function successfully were high turnover or shortage of staff, specifically other doctors (MOs) to address the clinical workload, as well as a restrictive managerial and/or policy environment (such as budgetary constraints, role confusion and inefficient support structures).

Role clarification and support were identified as enabling factors. Some DMs mentioned the mentoring support of senior FPs and other specialists to newly qualified FPs. Newly qualified FPs appeared to gradually embrace all of their six roles in an incremental process as they gained experience and maturity. An understanding of the complexity of the DHS environment was also seen as beneficial. FPs with leadership qualities, resilience and the ability to be change agents were seen as FPs able to shape their context. A supportive team and management were identified as pivotal enabling factors:

And I think I shared freely previously that we cannot expect that we put a new staff category on the service platform and we don't assist in defining roles and responsibilities. Because I feel as a district manager, that's your strategic, it's your responsibility, and it's a strategic function, to ensure that every staff category represented on the DHS platform needs to know exactly where does he or she fit in. And if you are poor at doing that it will pan out operationally.... It was a deliberate focus to ensure that we don't get it wrong, that we take everybody on this journey to ensure that the family physician is a recognised specialty in the district. (DM, Western Cape Province)

\section{DMs' message to training programmes}

The DMs appreciated that the FPs' training had prepared them to understand 'the bigger picture' of the DHS. Some DMs cautioned academic departments to select mature candidates with previous DHS exposure for the training programmes. Trainees need to embrace a community perspective and to look beyond facility-based care. Ongoing conversations were required to ensure that academic training programmes remain in step with the evolving service-delivery needs and expectations:

My assumption has always been to say, the doctor who is a family physician [has] the skills, but also you need the doctor that knows the territory ... because you find that we expect them as a consultant to be able to argue for things that we think are important for the district.... We feel as they come as the specialist, they have to make a tailor-made plan for the district and we work on that. (DM, Free State Province)

\section{Discussion}

\section{Key findings}

Interviews with DMs confirmed a number of benefits of FPs to the health system in South Africa: their ability to increase access to a more comprehensive and coordinated health service, to improve clinical care, to capacitate the healthcare team and facilitate clinical governance activities. The FPs' ability to act as a leader and to influence their colleagues was seen as a key factor in determining their impact on the health outcomes of the community served. Managers involved with integrating new FPs into the healthcare team needed to take cognisance of the variance in roles with different employment models, the need for initial role clarification and to support role maturation with experience over time. DMs agreed that the FPs, and their team members (including senior colleagues, other specialists, local and district managers), as well as the academic training coordinators should engage in ongoing conversations around role clarification, mentoring support (senior FPs) and role maturation (from clinician/consultant to clinical governance leader and trainer) as it applies to each local context. $8,24,43$ An approach that understands the contextual challenges and enabling factors will help amplify the contribution of FPs to strengthening the DHS. Figure 2 is based on the modified Donabedian causal chain by Lilford et al., ${ }^{44}$ and provides a visual summary of the key points highlighted by the DMs on the perceived impact of FPs and important issues to consider.

\section{Discussion of the findings in relation to the literature}

\section{Perceived impact on health system performance}

Three of the four domains of health system performance ${ }^{45}$ were benefited, namely access, coordination of care and comprehensiveness of care. The benefits to health system performance, described previously in the Western Cape Province, were echoed across the spectrum of district settings nationally. ${ }^{30,31}$ Continuity of care was not specifically mentioned by DMs in this study and FPs do not appear to be affecting this important dimension of effective primary care..$^{33}$ Continuity of care is a complex phenomenon and may be divided into relational continuity (a continuous therapeutic relationship with a designated healthcare team), informational continuity (information as the link between one provider and another, and between one healthcare event and another) and managerial continuity (continuity and consistency of clinical management within the healthcare team) ${ }^{46}$ Continuity is influenced by patient, provider and practice factors. ${ }^{47}$ In South Africa, primary care services at clinics and community health centres are struggling to cope with high patient volume, the complexity of undifferentiated problems, multiple co-morbidities and serious illness. ${ }^{8}$ Further research is required on how FPs, their teams and policy-makers may improve the continuity of care within the South African DHS. 


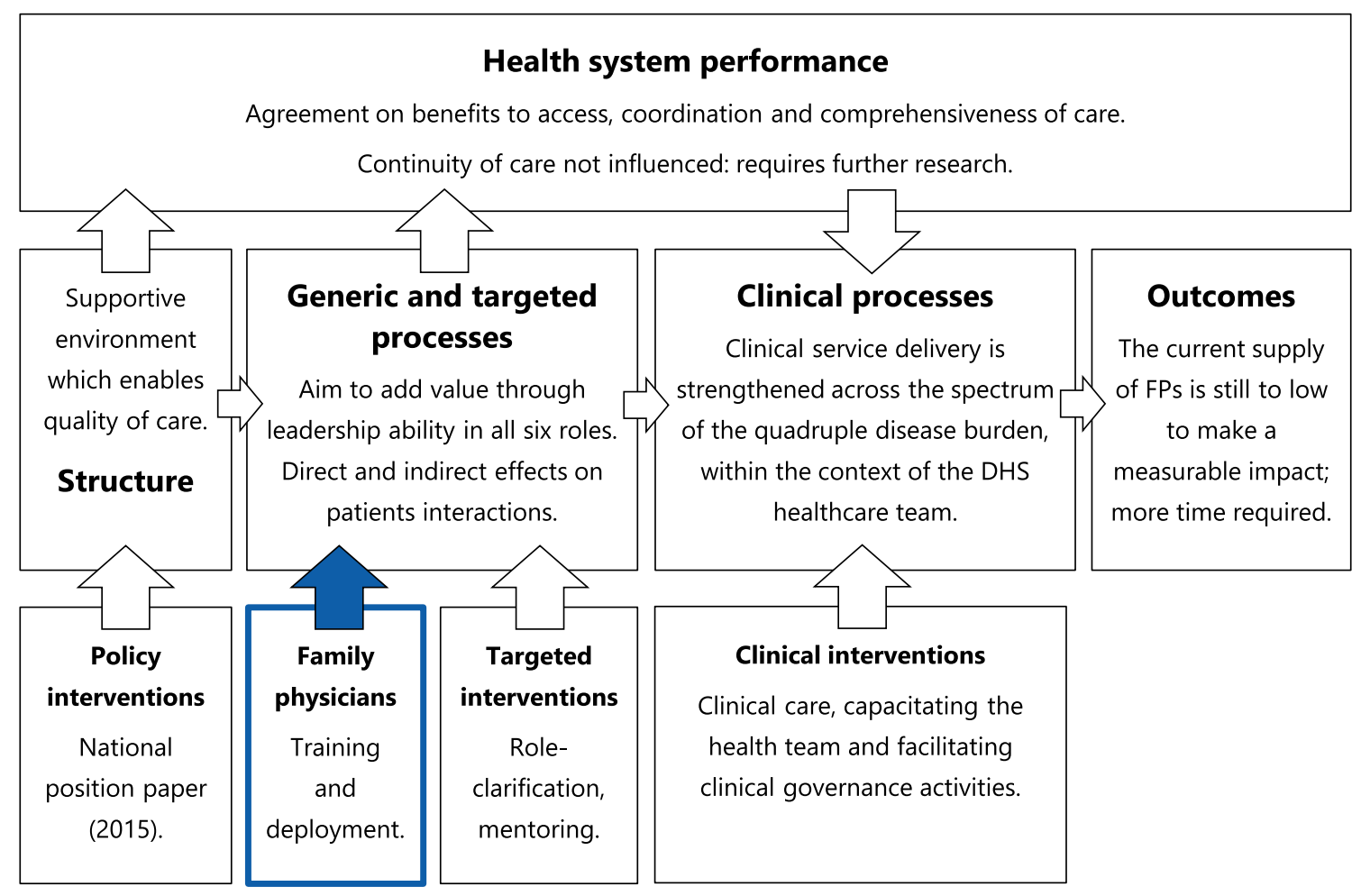

Figure 2: Visual summary of the key study findings.

\section{Perceived impact on clinical processes and health outcomes}

The DMs in the wider South African setting were in agreement with the previously published benefits of FPs to strengthening clinical service delivery across the spectrum of the quadruple disease burden. ${ }^{30,31}$ These benefits were ascribed to the effect of the six FP roles, which allowed the FP to have direct and indirect effects on patient interactions within the context of the DHS healthcare team. The FPs' training as expert generalists across 10 clinical domains enables them to care for the majority of health problems encountered in the DHS. ${ }^{8}$ DMs appreciated the FP's ability to bring a range of skills closer to the coalface of primary care, as described in the national position paper. ${ }^{7}$ DMs also appreciated the fact that the supply of FPs within the DHS was still too low to make a measurable impact and that more time is required to appreciate the full impact of their integration into the healthcare system. This is in keeping with the findings of an ecological study, which found little correlation between the supply of family physicians and routinely collected data on district performance. ${ }^{35}$

\section{Roles of family physicians}

The DMs appreciated how the six roles of the FP, which were agreed on by the South African academic family medicine departments and incorporated into the generic FP job description by the NDOH, enabled FPs to influence the DHS. Other studies have also shown that South African FPs are having a recognisable impact across all six roles which is also greater than that of the medical officers. ${ }^{33,34,48}$ DMs in this study appreciated that an FP could play a broader role than the clinical role represented by MOs (primary care doctors without postgraduate training, who are employed primarily to provide clinical care). DMs saw the contribution of FPs to COPC as their weakest role, although other studies at the level of the facility have seen FPs having a high impact in this area. ${ }^{34}$ DMs made the connections between the performance of these six roles and improvements in health system performance and clinical outcomes.

\section{Role of leadership within the DHS context}

The DMs provided rich data on the need for the FP to demonstrate leadership in collaboration with the local managers in order to create a supportive environment in which healthcare workers and the quality of their work could flourish. Collaborative leadership between FPs and the local managers has also been showcased in the Western Cape with regard to implementation of the clinical governance framework..$^{28}$ The importance and nature of leadership competencies in the training of FPs has also been emphasised recently and new learning outcomes created to guide the South African training programmes. ${ }^{21}$ The FP should add value through his/her leadership ability in all his/her roles, in keeping with a collaborative and complex adaptive leadership style..$^{21,49}$ The conversation around leadership should also include the need for the district health system to integrate with the educational system (academic family medicine departments) to enhance the support of the teaching and learning environment. This is needed to train the district workforce in the appropriate context, including future FPs, and for the educational system to understand the evolving needs of the district-level services. FPs across the country are also being trained as clinical trainers to facilitate workplace-based learning. .,22,50,51 $^{2}$

\section{Strengths and limitations}

The voices of eligible DMs who chose not to participate or who were not available might have provided further information, although it is unlikely that additional themes would have emerged, as data saturation was reached within the available interviews. Furthermore, the findings of this qualitative study triangulate well with other studies. ${ }^{24,30,31,33-35}$ The size of districts differs between provinces and this may have resulted in DMs having different levels of understanding of their FPs' impact. Some DMs were able to comment in more detail in relation to FPs employed at higher levels in their district, such as those FPs employed as the district FP or serving as a member of the DCST. DMs, however, are better placed to view their district as a whole system. This vantage point 
supported the researchers' decision to select DMs as key informants to address the study's aim and objectives.

\section{Recommendations}

This study supports the need to employ FPs at scale within the South African district health system as outlined in the national position paper, namely that 'as a country, initially the short-term goal should be for one family physician to be employed per subdistrict and one per district hospital'.

Newly appointed FPs need an active process of support from and role clarification with their healthcare teams to establish themselves in the health system and to mature in all their different roles. Further research may be needed to understand and conceptualise this process more clearly.

More attention should be given to developing continuity of care and to the contribution of the FP towards this goal.

The importance of FPs developing leadership competencies was reinforced and the need for training in this across all their roles.

The need to integrate the educational system with the district health system was clear in order to create an appropriately trained workforce, including the FP.

\section{Conclusion}

DMs affirmed the importance of all six roles of the FP and the direct and indirect ways in which they contribute to strengthening health system performance and clinical outcomes. FPs were seen as important clinical leaders within the district healthcare team. Newly appointed FPs needed support to clarify their roles within the healthcare team and to mature across all their roles. The study supports the need to employ FPs at scale within the South African district health system according to the national position paper on family medicine.

\author{
Abbreviations \\ AIDS : acquired immune deficiency syndrome \\ CHC: community health centre \\ COPC: community-oriented primary care \\ COREQ : consolidated criteria for reporting qualitative \\ research \\ DCSTs: district clinical specialist teams \\ $\mathrm{DH}$ : district hospital \\ DHS: district health system \\ DMs : district managers \\ FPs : family physicians \\ HIV : human immunodeficiency virus \\ MOs : medical officers \\ MOU : midwife obstetrics unit \\ NCDs: non-communicable diseases \\ $\mathrm{NDOH}$ : South African National Department of Health \\ $\mathrm{NHI}$ : National Health Insurance \\ $\mathrm{PHC}$ : primary health care \\ STIs : sexually transmitted illnesses \\ WBOTs : ward-based outreach teams \\ WHO : World Health Organization
}

Acknowledgements - The authors wish to thank the district managers for agreeing to participate in the study. The authors also wish to thank the members of the research team for their help with conducting the interviews: Dr L Campbell (University of KwaZulu-Natal), Mr B Mashaba (Sefako Makgatho Health Sciences University), Sr G Mathebula and Dr P van Niekerk (University of Pretoria), and Ms T Rwafa (University of the Witwatersrand). In addition, the authors would also like to thank Ms S Munshi (University of the Witwatersrand) for her help during the initial planning phase of the study.

This study was conducted with the financial assistance of the European Union. The contents of this document are the sole responsibility of the authors and can under no circumstances be regarded as reflecting the position of the European Union. Additional funding was received from the Discovery Foundation (South Africa) and the Faculty of Medicine and Health Sciences, Stellenbosch University, South Africa.

Conflict of interest statement - The authors declare that they have no financial or personal relationship(s) that may have inappropriately influenced them in writing this article.

\section{Supplementary material}

Supplementary material for this article can be accessed at: https://doi.10.1080/20786190.2017.1348047.

\section{ORCID}

KB Von Pressentin (D) http://orcid.org/0000-0001-5965-9721

L Baldwin-Ragaven (D) http://orcid.org/0000-0002-6744-3768

I Govender (iD http://orcid.org/0000-0003-0126-8087

WJ Steinberg iD http://orcid.org/0000-0001-9944-1807

\section{References}

1. World Health Organization. Declaration of Alma-Ata: International Conference on Primary Health Care, Alma-Ata, USSR, 6-12 September 1978 [cited 2017 April 18]. Available from: http://www.who.int/ publications/almaata_declaration en.pdf.

2. World Health Organization. The World Health Report 2008: Primary Health Care Now More Than Ever. Geneva: Switzerland; 2008.

3. World Health Organization. World Health Report: health systems financing: the path to universal coverage [Internet]. c2010 [cited 2017 April 18]. Available from: http://www.who.int/whr/2010/whr10_en.pdf.

4. Pettigrew LM, De Maeseneer J, Anderson Ml, et al. Primary health care and the Sustainable Development Goals. The Lancet. 2015 Nov 28;386(10009):2119-21. https://doi.org/10.1016/S0140-6736(15)00949-6

5. World Health Organization. The World Health Report 2006: Working Together For Health [Internet]. c2006 [cited 2017 April 18]. Available from: http://www.who.int/whr/2006/whr06_en.pdf.

6. MayosiBM,Flisher AJ, Lalloo UG, etal.The burden of non-communicable diseases in South Africa. The Lancet. 2009 Sep 18;374(9693): 934-47. https://doi.org/10.1016/S0140-6736(09)61087-4

7. Mash R. The contribution of family medicine to African health systems. Af J Primary Health Care Fam Med. 2016;8(1):1-2.

8. Mash R, Ogunbanjo G, Naidoo SS, et al. The contribution of family physicians to district health services: a national position paper for South Africa: forum. South Af Fam Pract. 2015 May 1;57(3):54-61.

9. World Health Organization. Primary Health care, including health system strengthening. World Health Assembly Resolution. 2009 May;6212.

10. The Contribution of Family Medicine to Improving Health Systems: A Guidebook from the World Organization of Family Doctors, Second Edition. Radcliffe: Radcliffe Health; 2013.

11. Macinko J, Starfield B, Shi L. Quantifying the health benefits of primary care physician supply in the United States. Int J Health Serv. 2007 Jan;37(1):111-26. https://doi.org/10.2190/3431-G6T7-37M8-P224

12. Moosa S, Wojczewski S, Hoffmann $K$, et al. Why there is an inverse primary-care law in Africa. Lancet Global Health. 2013;1(6):e332-3. https://doi.org/10.1016/S2214-109X(13)70119-0 
13. Moosa S, Downing R, Mash B, Reid S, Pentz S, Essuman A. Understanding of family medicine in Africa: a qualitative study of leaders' views. Br J Gen Pract. 2013 Mar 1;63(608):e209-16. https://doi.org/10.3399/bjgp13X664261

14. Mash R, Almeida M, Wong WC, et al. The roles and training of primary care doctors: China, India, Brazil and South Africa. Hum Res Health. 2015 Dec 4;13(1):93. https://doi.org/10.1186/s12960-015-0090-7

15. Ogunbanjo GA, Couper I. The Rustenburg resolution: inequality in health care in South Africa: guest editorial. S Afr Fam Pract. 2008 Sep/ Oct 50;(5):42.

16. Hugo JF, Couper ID, Thigiti J, Loeliger S. Equity in health care: does family medicine have a role?: conference proceedings. Af J Primary Health Care Fam Med. 2010 Jan 1;2(1):1-3.

17. Mash RB, Reid S. Statement of consensus on family medicine in Africa: conference report. Af J Primary Health Care Fam Med. 2010 Jan 1;2(1):1-4.

18. Mash R, Downing R, Moosa S, De Maeseneer J. Exploring the key principles of Family Medicine in sub-Saharan Africa: international Delphi consensus process. South Af Fam Pract. 2008 May 1;50(3):60-5. https://doi.org/10.1080/20786204.2008.10873720

19. Hellenberg D, Gibbs T. Developing family medicine in South Africa: a new and important step for medical education. Med Teach. 2007 Jan 1;29(9-10):897-900. https://doi.org/10.1080/01421590701827890

20. Couper I, Mash B. Obtaining consensus on core clinical skills for training in family medicine: open forum. South Af Fam Pract. 2008 Nov 1;50(6):69-73. https://doi.org/10.1080/20786204.2008.10873796

21. Mash R, Blitz J, Malan Z, Von Pressentin K. Leadership and governance: learning outcomes and competencies required of the family physician in the district health system. South Af Fam Pract. 2016 Nov 18;58(6):232-5. https://doi.org/10.1080/20786190.2016.1148338

22. De Maeseneer J. Scaling up family medicine and primary health care in Africa: statement of the primafamed network, Victoria Falls, Zimbabwe. Af J Primary Health Care Fam Med. 2013;5(1): 61-3.

23. Flinkenflögel $M$, Essuman $A$, Chege $P$, Ayankogbe $O$, De Maeseneer J. Family medicine training in sub-Saharan Africa: South-South cooperation in the Primafamed project as strategy for development. Fam Pract. 2014 May 23:cmu014.

24. Moosa S, Mash B, Derese A, Peersman W. The views of key leaders in South Africa on implementation of family medicine: critical role in the district health system. BMC Fam Pract. 2014 Jun 25;15(1):125. https://doi.org/10.1186/1471-2296-15-125

25. Mash R, Von Pressentin K. Family medicine in South Africa: exploring future scenarios. South Af Fam Pract. 2017 Jan;28:1-4.

26. National Department of Health. Human resources for health for South Africa: Strategy for the Health Sector 2012/13-2016/17. Pretoria: National Department of Health; 2011.

27. National Planning Commission. National Development Plan 2030: Our future-make it work. Pretoria: Presidency of South Africa; 2012.

28. GunstC,MashRJ,PhillipsLC.Areflectiononthepracticalimplementation of the clinical governance framework in the Cape Winelands District of the Western Cape. South Af Fam Pract. 2016 Nov 18;58(6):236-41. https://doi.org/10.1080/20786190.2016.1151642

29. National Department of Health. Handbook for district clinical specialist teams. Pretoria: National Department of Health; 2014.

30. Swanepoel M, Mash B, Naledi T. Assessment of the impact of family physicians in the district health system of the Western Cape, South Africa. Af J Primary Health Care Fam Med. 2014 Jan;6(1):1-8.

31. Ferreira G, Mash RJ. Assessment of the impact of family physicians in the district health system of the Western Cape, South Africa [Internet]. Stellenbosch University; 2015 [cited 2017 April 18]. Available from: http://scholar.sun.ac.za/handle/10019.1/99325.

32. Division of Family Medicine and Primary Care (Stellenbosch University). Strengthening primary health care through primary care doctors and family physicians (EuropeAid-funded project) [Internet]. 2016 [cited 2017 April 18]. Available from: https://www.sun.ac.za/ english/faculty/healthsciences/FamilyMedicine and Primary Care/ Pages/EuropeAid.aspx .
33. Von Pressentin KB, Mash RJ, Baldwin-Ragaven L, et al. Measuring the influence of family physicians within the South African district health system: a cross-sectional observational study. 2017; Submitted.

34. Von Pressentin KB, Mash RJ, Baldwin-Ragaven L, et al. The perceived impact of family physicians on the district health system in South Africa: a cross-sectional survey. 2017; Submitted.

35. Von Pressentin KB, Mash RJ, Esterhuizen TM. Examining the influence of family physician supply on district health system performance in South Africa: an ecological analysis of key health indicators. Af J Primary Health Care Fam Med. 2017;9(1):10.

36. Tong A, Sainsbury P, Craig J. Consolidated criteria for reporting qualitative research (COREQ): a 32-item checklist for interviews and focus groups. Int J Qual Health Care. 2007 Dec 1;19(6): 349-57. https://doi.org/10.1093/intqhc/mzm042

37. National Department of Health. National eHealth Strategy South Africa 2012-2016. Pretoria: National Department of Health; 2012.

38. National Health Insurance in South Africa. Policy (white) Paper. Government Notice No. 1230, Government Gazette No. 39506. Pretoria: National Department of Health; 2015 December 11.

39. Mash B, Fairall L, Adejayan O, et al. A morbidity survey of South African primary care. PloS One. 2012 Mar 16;7(3):e32358. https://doi.org/10.1371/journal.pone.0032358

40. Kinkel HF, Marcus $\mathrm{T}$, Bam N, et al. Community oriented primary care in Tshwane District, South Africa: assessing the first phase of implementation: original research. Af J Primary Health Care Fam Med. 2013 Jan 1;5(1):1-9.

41. Ritchie J, Spencer L. Qualitative data analysis for applied policy research. In: Anal Qual Data. 1994:173-94.

42. Scientific Software Development GmbH. ATLAS.ti, Version 7.5.17 [software]. Berlin, Germany: GmbH. c2017 [cited 2017 April 18]. Available from: https://atlasti.com.

43. Mash B. Reflections on the development of family medicine in the Western Cape: a 15-year review. South Af Family Pract. 2011 Nov 1;53(6): 557-62. https://doi.org/10.1080/20786204.2011.10874152

44. Lilford RJ, Chilton PJ, Hemming $\mathrm{K}$, et al. Evaluating policy and service interventions: framework to guide selection and interpretation of study end points. BMJ. 2010 Aug;27(341): c4413. https://doi.org/10.1136/bmj.c4413

45. Kringos DS, Boerma WG, Hutchinson A, et al. The breadth of primary care: a systematic literature review of its core dimensions. BMC Health Serv Res. 2010 Mar 13;10(1):65. https://doi.org/10.1186/1472-696310-65

46. Haggerty JL, Reid RJ, Freeman GK, et al. Continuity of care: a multidisciplinary review. BMJ. Br Med J. 2003 Nov 20;327(7425): 1219. https://doi.org/10.1136/bmj.327.7425.1219

47. Kristjansson E, Hogg W, Dahrouge $S$, et al. Predictors of relational continuity in primary care: patient, provider and practice factors. BMC Family Pract. 2013 May 31;14(1): 72. https://doi.org/10.1186/1471-2296-14-72

48. Pasio KS, Mash R, Naledi T. Development of a family physician impact assessment tool in the district health system of the Western Cape Province, South Africa. BMC Family Pract. 2014; Dec 1215(1): 204. https://doi.org/10.1186/s12875-014-0204-7

49. Weller J, Boyd M, Cumin D. Teams, tribes and patient safety: overcoming barriers to effective teamwork in healthcare. Postgraduate Med J. 2014 Mar 1;90(1061):149-54. https://doi. org/10.1136/postgradmedj-2012-131168

50. De Villiers MR, Cilliers FJ, Coetzee F, et al. Equipping family physician traineesasteachers:aqualitativeevaluation ofatwelve-weekmoduleon teaching and learning. BMC Medical Education. 2014 Oct 22;14(1):228. https://doi.org/10.1186/1472-6920-14-228

51. Mash RJ, De Villiers MR, Moodley K, et al. Guiding the development of familymedicinetraininginAfricathroughcollaborationwiththeMedical Education Partnership Initiative. Acad Med. 2014 Aug 1;89(8): S73-7. https://doi.org/10.1097/ACM.0000000000000328 